\title{
Pilot Study on the Effect of Yasiin Recitation on the Haemodynamics of Ventilated Patients
}

\author{
Ariff MS ${ }^{\mathrm{a}}$, Mai Ashikin NT ${ }^{\mathrm{b}}$, Maryamjameelah $\mathrm{R}^{\mathrm{c}}$, Bushra Jd, Wan Azman WA \\ a Department of Orthopaedics, Traumatology and Rehabilitation, Kulliyyah of Medicine, International Islamic \\ University Malaysia \\ ${ }^{b}$ Department of Paediatrics, Kulliyyah of Medicine, International Islamic University Malaysia \\ c Department of Paediatrics, Hospital Sungai Buloh, Selangor, Malaysia \\ ${ }^{d}$ Faculty of Medicine, Universiti Teknologi MARA (UiTM), Sungai Buloh Campus, Selangor, Malaysia \\ e Department of Medicine, Faculty of Medicine, University Malaya, Malaysia
}

\begin{abstract}
Introduction: Qur'anic verses recitations to ill patients are practiced by many Muslims as a form of healing and worship. The effectiveness has been observed in many medical institutions; however, it has never been objectively measured and documented. This pilot study was conducted to construct a methodological approach to evaluate the therapeutic effects of Yasiin recitation on the haemodynamics of critically ill patients. Methods: Ventilated Muslim patients in coronary care unit of a teaching hospital were evaluated. Yasiin was recited twice; by one of the researchers and then by the patients' relatives. Mean arterial blood pressure, pulse rate, oxygen saturation level and electrocardiographic changes, were observed. The difference of the parameters before and during recitation was analysed. Results: Five patients fulfilling the selection criteria were selected; two acute myocardial infarctions, two congestive cardiac failures, and a third-degree atrioventricular block. Based on a non-parametric two-related-sample test, the haemodynamic parameters were not significantly affected by Yaasiin recitation. At the end of the study, two of the patients passed away, one patient was extubated and survived. Two patients were still on ventilators when the study had been completed. Limitations in the study were observed and highlighted in explaining the equivocal results. Conclusions: The effect of Yasiin recitation on heamodynamics of patients was not proven in this study. Further refinements might be needed based upon the observation on limitations encountered. It is hoped that this humble effort would pave the way for further studies to explore this field.
\end{abstract}

KEYWORDS: Haemodynamic study, complementary alternative medicine, religion and medicine, spiritual therapies

\section{INTRODUCTION}

Complementary and alternative medicine (CAM) is becoming increasingly popular worldwide, sought frequently for chronic conditions such as back problems, anxiety, depression, and headaches as well as for cancer. ${ }^{1-4}$ Numerous studies have been conducted to prove that CAM can go hand in hand with current medical therapies. In a study investigating the prevalence, pattern, perceived benefits, and predictors of the use of CAM among middle-aged and older patients prior to cardiac surgery, $80.9 \%$ confirmed CAM use. ${ }^{3}$ McCurdy et al. ${ }^{5}$

\section{Corresponding author:}

Dr. Mohd Ariff Sharifudin

Department of Orthopaedics, Traumatology and

Rehabilitation,

Kulliyyah of Medicine, International Islamic

University Malaysia (IIUM),

Jalan Sultan Ahmad Shah,

Bandar Indera Mahkota,

25200 Kuantan, Pahang,

MALAYSIA.

Tel: 0060193352499

Email: ariffs@iium.edu.my found that $47 \%$ of respondents believed the therapies used might be helpful and probably would do no harm, and would definitely help cure the condition (24\%). There are ample evidences to suggest that CAM therapy have large beneficial health effects. According to a study on music therapy, it was shown that it has an effective nursing intervention in decreasing anxiety inventilator-dependant patients. The authors recommended its use to be incorporated into the care of mechanically ventilated patient. ${ }^{6}$ Positive effects include altering the patients' mental and physical states of well-being, motivating them to improve physically, prepare for active living, improve their coping mechanisms, and enhance their experiences of hospitalization. ${ }^{4}$ Beta-endorphin was lowered significantly after music therapy despite physical activity. ${ }^{7}$ However, the definition of CAM therapies is not standardized, making comparisons between studies difficult. Various terms used in literature, including prayer, faith healing, spiritual healing, megavitamins/ minerals, relaxation techniques, herbal medicines/ teas and the use of music. ${ }^{1-12}$ In particular, the denotation of prayer or religion as CAM is controversial. 
Prayer is an ancient and widely used intervention for alleviating illness and promoting good health. ${ }^{9,13}$ Religion and spirituality are known to play important roles in coping with cancer in adults ${ }^{8}$ and children, ${ }^{5,12}$ although objective research is difficult to perform and is therefore sparse in the scientific and medical literature. In children, these two components are, however, becoming recognized as important factors of the overall health of children, and it has been suggested that paediatricians incorporate spirituality into clinical practice. ${ }^{12}$ In Islamic scriptures, healing was mentioned in two large categories; spiritual healing and physical healing. Both preventive and therapeutic medicines are also discussed. ${ }^{9}$ Qur'anic verses recitations to ill patients, for example, are practiced by many Muslims as a form of healing and worship.

Until today, the effectiveness has been observed in many medical institutions; however, it has never been objectively measured and documented. This study was performed with two main objectives. We would like to construct a novel methodological approach to evaluate the therapeutic effect of Qur'anic recitation on ill patients, in particular the critically ill patients. Specifically, we would like to document the association of Yasiin recitation on the haemodynamics of ventilated patients. Yasiin is a chapter from the Qur'an, which is traditionally recited to ill patients in Muslim community. The hypothesis was that Yaasiin recitation affects haemodynamics of ventilated patients.

\section{MATERIALS AND METHODS}

This study was approved by an institutional review board. We evaluated ventilated Muslim patients in the medical wards of a teaching hospital. Only Muslim patients were chosen to avoid ethical issues. Patients whose families were unavailable or refused to give consent and patients with low readings not recordable on the bedside monitors were excluded from the study. In view of the limited number of patients available, patients were not standardized to a specific medical problem. This study design enabled us to conduct the study in a short period of time and involved a relatively low cost. A pre-test was conducted on another ventilated patient prior to the actual study. The pre-test was done to identify problems with the method of study and consent taking. Improvements were made especially regarding the technical problems encountered in measuring the haemodynamic parameters.
Selected patients were on bedside monitors, which were preset according to the designed setting. Measurements of four parameters were taken; mean arterial blood pressure (MABP), pulse rate (PR), oxygen saturation level (SPO2) and electrocardiographic (ECG) changes. Two sets of data were taken from each patient and recorded in a designated form. The first sets were taken during recitation of Yaasiin by the authors and the second sets during recitation of Yasiin by patient's relatives. Each set consisted of five readings of each parameter at a two-minute interval between each session. The readings were taken before and during the recitation of Yasiin with five-minute interval between each session.

The difference of the parameters before and during recitation was calculated and analysed. The outcome of the ventilation was also in the end observed, whether the patients were extubated and survived, or passed away.

\section{RESULTS}

Only five patients fulfilled the selection criteria of the study. All five were male patients with age range between 29-61 years old. Two patients had acute myocardial infarction with one patient complicated with cardiogenic shock. Another two patients were ventilated for congestive cardiac failure secondary to dilated cardiomyopathy and chronic rheumatic heart disease. The final patient had a third-degree atrioventricular block. Yasiin was recited at a nonspecific time during their period of ventilation (Table 1). Comparison of mean parameters before and during Yaasiin recitation, and between recitation by researchers and patients' relatives are summarized in Table 2. There was no statistical difference between mean of all four parameters observed before and during Yaasiin recitation based on non-parametric two-related-sample Wilcoxon Signed Ranks test. These were observed during recitation by the researchers as well as patients' relatives. In addition, various outcomes of the patients were observed at the end of the study. Two of the patients passed away, one patient was extubated and survived. Another two patients were still on ventilators when the study had been completed. 
Table 1. Patient demographics

\begin{tabular}{lllcl}
\hline No. & Diagnosis & $\begin{array}{l}\text { Gender/ } \\
\text { Age (years) }\end{array}$ & $\begin{array}{l}\text { Days of ventilation prior to } \\
\text { Yaasiin recitation }\end{array}$ & $\begin{array}{l}\text { Outcomes (following } \\
\text { recitation) }\end{array}$ \\
\hline 1 & Acute myocardial infarction & Male, 54 & Three days & $\begin{array}{l}\text { Extubated after five } \\
\text { days }\end{array}$ \\
2 & $\begin{array}{l}\text { Acute myocardial infarction } \\
\text { with cardiogenic shock }\end{array}$ & Male, 61 & Seven days & Died after one day \\
3 & $\begin{array}{l}\text { Congestive cardiac failure } \\
\text { secondary to dilated } \\
\text { Cardiomyopathy }\end{array}$ & Male, 55 & Five days & Still ventilated \\
4 & $\begin{array}{l}\text { Congestive cardiac failure } \\
\text { with underlying chronic } \\
\text { rheumatic heart disease }\end{array}$ & Male, 29 & One day & Still ventilated \\
Third degree atrioventricular & Male, 51 & Three days & Died after two \\
block & & days \\
\hline
\end{tabular}

Table 2. Comparison of mean parameters before and during Yaasiin recitation by researchers and patients' relatives

By Authors

Haemodynamic Parameter
By Patients' Relatives

$\begin{array}{lll}\text { Mean (during) - } & \text { Mean (during) - } \\ \text { Mean (pre) } & p \text { value } & \text { Mean (pre) }\end{array}$

p value

$\begin{array}{lllll}\text { Mean arterial blood pressure (MABP) } & -0.406 & 0.684 & -1.753 & 0.080 \\ \text { Pulse Rate (PR) } & -0.674 & 0.500 & 0.000 & 1.000 \\ \text { Oxygen saturation level (SPO2) } & 0.000 & 1.000 & -1.000 & 0.317 \\ \text { Electrocardiographic changes (ECG) } & 0.000 & 1.000 & -1.000 & 0.317\end{array}$

$P$ value obtained by Wilcoxon Signed Ranks test

\section{DISCUSSION}

Inconclusive results were also observed in another study on effectiveness of prayer as an additional intervention for those with health problems already receiving standard medical care. ${ }^{9}$ Hence, the strong belief on the effect of Qur'anic recitation should not waver just based on this one particular study. It is all too clear that a perfect ideality is only rarely achieved. This study had several limitations. Looking at sample factor, the number of patients available for this study depends solely on the prevalence of ventilated patients in the coronary care unit over a short period of time. It was also performed at the terminal stage of the illness. Morbid status of the patient would sometime prevent them from being chosen as a sample. As mentioned earlier, patients who were too ill, with haemodynamic parameters not recordable on the automatic continuous monitoring would not be included in the sample frame. It must also be borne in mind that the study was done on patients who were on conventional hospital treatment. Therefore, the effects of this medical therapy, for example, the drugs, would overlap with any effect that might be observed inrelation to the study. They were most of the time infused with medications; the commonest observed in this setting were adrenergic drugs such as noradrenalin, or analgesics, such as morphine. Furthermore, routine medical procedures were sometimes done during Yaasiin recitation, be it venepuncture or chest physiotherapy, thus affecting the patient in some way or another.

Patient's family emotion must also be taken into consideration. They were usually anxious to comfort and help their ill loved ones during this critical period, and they have their own way of showing their concern, by massaging the patients, or by just softly 
talking to them. As all these practices have also been considered as part of CAM, they could mask or even overlap with the possible effects of Yasiin recitation for the patients.

The study design also had its own imperfection. In haemodynamic parameters monitoring, non-invasive systems may be acceptable alternatives where invasive monitoring is not available, ${ }^{14}$ and this was used in our study. However, literature stated that invasive blood pressure measurement is used in patients with unstable haemodynamics, and the demand of the accuracy of these measurements is high. ${ }^{15}$ Additionally, some of the readings may not be accurately measured by the bedside monitor. A specific example would be inaccurate measurement of oxygen saturation level in a restless patient whereby the oxygen detector kept slipping off his finger. Therefore, one of the greatest limitations of this study, which perhaps had contributed to the insignificant result, was the use of non-invasive haemodynamic parameters measurement. The study would also have been more reliable if the subjects were controlled. Means, medians or any other central tendency measurements could only ideally be done across a group of subjects with similar morbidity and degree of illness. Apart from that, as there had been no other established similar study conducted, the ideal time interval for the whole session with the patient could not be ascertained. It was at first visioned that a longer time could be allowed for intervals between each set of readings.

However, time was a critical factor for these ventilated patients, thus this ideal setting could not be reached. It was also impossible to get a conducive setting for the study, as patients were exposed to other auditory stimuli common in a general medical ward. It would have been best if these patients were placed in isolated individual cubicles. A study done had shown that music therapy has an effective nursing intervention in decreasing anxiety in ventilatordependent patients, and should be incorporated into the care of mechanically ventilated patient ${ }^{6}$. As this study did not compare the effect of music therapy and Yasiin recitation, it could not be scientifically proven that any possible positive outcome was resulted by Qur'anic verse recitation itself as opposed to its soothing rhythm. It would also be of great benefit to see whether Qur'anic recitation by the ones closest to the patient affects him more in comparison to recitation by a stranger. Another aspect that can be explored is the effect of repetitive recitation of Yasiin on an ill patient, whether several readings of Yasiin would benefit the patient more as compared to a single reading.

\section{CONCLUSION}

The study did not prove the effect of Yasiin recitation on haemodynamics of ventilated patients. But this should not discourage the practice of reciting Qur'an to the ill ones. It is hoped that this study would pave the way in welcoming further efforts to explore this field. Further refinements might be needed based on our observation on the limitations we faced. If prayer is seen as a human endeavour, scientifically it may or may not be beneficial, and further trials could uncover this. It could be the case that any effects are due to elements beyond present scientific understanding that will, in time, be understood. If any benefit derives from God's response to prayer, it may be beyond any such trials to prove or disprove. ${ }^{9}$ As a poet Alfred Tennyson wrote, "Many things are wrought by prayer than this world dreams of."

\section{ACKNOWLEDGEMENT}

The authors would like to express their gratitude to Prof. Dato' Dr Ariff Osman of International Islamic University Malaysia for his support in completing this study.

\section{REFERENCES}

1. Ernst E, Cassileth BR. The prevalence of complementary/alternative medicine in cancer: a systematic review. Cancer 1998; 83:777-82.

2. Eisenberg DM, Davis RB, Ettner SL, et al. Trends in alternative medicine use in the United States, 1990-1997: results of a follow-up national survey. JAMA 1998; 280:1569-75.

3. Ai AL, Bolling SF. The use of complementary and alternative therapies among middle-aged and older cardiac patients. Am J Med Qual 2002; 17:21-7.

4. Hogan BE. Soul music in the twilight years: music therapy and the dying process. Topics in Geriatric Rehabilitation 2003; 19:275-81.

5. McCurdy EA, Spangler JG, Wofford MM, Chauvenet AR, McLean TW. Religiosity is associated with the use of complementary medical therapies by pediatric oncology patients. J Pediatr Hematol Oncol 2003; 25:125-9.

6. Wong HL, Lopez-Nahas V, Molassiotis A. Effects of music therapy on anxiety in ventilator-dependent patients. Heart Lung 2001; 30:376-87.

7. Vollert JO, Stork T, Rose M, Mockel M. Music as adjuvant therapy for coronary heart disease. Therapeutic music lowers anxiety, stress and betaendorphin concentrations in patients from a coronary support group. Dtsch Med Wochenschr 2003; 128:2712-6. [German]

8. Tatsumura Y, Maskarinec G, Shumay DM, Kakai H. Religious and spiritual resources, CAM, and conventional treatment in the lives of cancer patients. Altern Ther Health Med 2003; 9:64-71.

9. Roberts L, Ahmed I, Hall S. Intercessory prayer for the alleviation of ill health. Cochrane Database Syst Rev 2000:CD000368.

10. Mytko JJ, Knight SJ. Body, mind and spirit: towards the integration of religiosity and spirituality in cancer quality of life research. Psychooncology 1999; 8:439-50. 
11. Spilka B, Zwartjes WJ, Zwartjes GM. The role of religion in coping with childhood cancer. Pastoral Psychology 1991; 39:295-304.

12. Barnes LL, Plotnikoff GA, Fox K, Pendleton S. Spirituality, religion, and pediatrics: intersecting worlds of healing. Pediatrics 2000; 106:899-908.

13. Loukas M, Saad Y, Tubbs RS, Shoja MM. The heart and cardiovascular system in the Qur'an and Hadeeth. Int J Cardiol 2010; 140:19-23.

14. Shoemaker WC, Belzberg H, Wo CC, et al. Multicenter study of noninvasive monitoring systems as alternatives to invasive monitoring of acutely ill emergency patients. Chest 1998; 114:1643-52.

15. Todorovic M, Jensen EW, Thogersen C. Evaluation of dynamic performance in liquid-filled catheter systems for measuring invasive blood pressure. Int J Clin Monit Comput 1996; 13:173-8. 